\title{
Optimization of in vitro fertilization technique for oocytes of indigenous zebu cows
}

\author{
Mohammad Moshiur Rahman, Md. Masudur Rahman, Nasrin Sultana Juyena and \\ Mohammad Musharraf Uddin Bhuiyan*
}

Department of Surgery and Obstetrics, Faculty of Veterinary Science, Bangladesh Agricultural University, Mymensingh 2202, Bangladesh

Received March 11, 2020

Revised May 30, 2020

Accepted June 1, 2020

\section{*Correspondence}

Mohammad Musharraf Uddin Bhuiyan

E-mail: mmubhuiyan@gmail.com

ORCID

https://orcid.org/0000-0002-0870-186X
ABSTRACT The research work was undertaken to determine an effective fertilization medium, sperm separation method and sperm capacitating agent for optimum in vitro fertilization (IVF) rates of indigenous zebu cow oocytes. In experiment 1, tissue culture medium (TCM 199), Tyrode's albumin lactate pyruvate (TALP) and Brackett and Oliphant (BO) medium were used as basic medium for IVF of oocytes of indigenous zebu cows. In experiment 2 , three sperm separation methods namely centrifugation, swim up and percoll gradient methods were used for separation of motile and viable spermatozoa for IVF. In experiment 3, for capacitation of spermatozoa, IVF medium supplemented with the heparin, mixture of penicillamine, hypotaurine and epinephrine (PHE) or the combination of heparin with PHE were used for fertilization. In vitro culture (IVC) of presumptive zygotes was done in modified synthetic oviduct fluid (mSOF) medium using standard procedure $24 \mathrm{~h}$ after sperm-oocytes co-culture. The cleavage rate was determined to evaluate the efficacy of fertilization medium, sperm separation method and sperm capacitating agent $24 \mathrm{~h}$ after IVC. The cleavage rate was higher in oocytes fertilized in TALP (63.3\%) than in TCM 199 (47.5\%) ( $p<0.05)$. The cleavage rate was higher in oocytes fertilized by spermatozoa separated by percoll gradient method $(62.3 \%)$ than by centrifugation $(51.6 \%)(p<0.05)$. The cleavage rate of oocytes was higher when insemination was done with spermatozoa capacitated in TALP supplemented with heparin and PHE (61.3\%) compared to control $(40.9 \%)(p<0.05)$. In conclusions, TALP based medium and percoll gradient sperm separation followed by capacitation with combination of heparin and PHE are suitable for IVF of indigenous zebu cow oocytes in Bangladesh.

Keywords: cleavage rate, in vitro fertilization, zebu cows

\section{INTRODUCTION}

Fertilization is a multifactorial and complicated process that includes sperm-ovum interaction, fusion and initiation of embryo development. Fertilization of oocytes in animals can be made by either in vivo or in vitro technique. In vitro fertilization (IVF) is regarded as a well es- tablished technique for getting offspring from infertile, low reproductive and endangered animals, and also for evaluation of fertilization mechanisms. Optimization of factors and techniques related to the fertilization will make the IVF more efficient and consistent. The IVF media, vitality and number of motile spermatozoa, sperm capacitation agent and duration of sperm-oocytes co- 
incubation are considered as important factors for in vitro embryo production in animals (Sakkas, 2001).

From the first IVF to the present, many chemical and technical changes were made to improve the fertilization in the laboratory (Bavister, 2002). Since long time, the IVF media have been formulated with the distinct goal of providing favorable conditions for capacitated spermatozoa to fertilize matured oocytes. Moreover, the IVF medium must play an important role not only for the separation of frozen-thawed motile sperm from their cryoprotectants but also for providing conditions meeting the appropriate physiological requirements for metabolic activities of both spermatozoa and oocytes during IVF incubation. These conditions are provided by the female's reproductive tract in vivo, whereas, these need to be mimicked by IVF medium in vitro (Adeoya-Osiguwa and Fraser, 2002).

Separation of progressive motile and morphologically viable normal spermatozoa from frozen thawed semen is another important step for success of IVF. For this reason, sperm separation methods have a very important role in IVF of oocytes. Separation of spermatozoa collects motile spermatozoa from non-motile ones, removes seminal plasma, cryoprotectives, other backdrop materials and debris, and also at the same time initiates sperm capacitation (Centola et al., 1998). Many sperm separation methods such as sperm washing (Rodriguez-Martinez et al., 1997), migration of spermatozoa by swim up technique (Morell and Rodriguez-Martinez, 2010) separation of spermatozoa through density gradient layers using percoll (Samardzija et al., 2006) and BoviPure ${ }^{\circledR}$ (Karadjole et al., 2010), selective filters namely Sephadex (Correa and Zavos, 1996) and swim up with the addition of hyaluronic acid (Leibfried-Rutledge et al., 1989) have been developed.

Capacitation is a critical biological process in spermatozoa to acquire the ability to fertilize the IVM oocytes. There are a number of chemical agents that are known to induced capacitation such as glycosaminoglycans including heparin (Parrish et al., 1986), and penicillamine, hypotaurine and epinephrine (PHE) or mixture of them (Miller et al., 1994). So far, very preliminary works on IVF of indigenous Zebu oocytes have been done in Bangladesh (Islam et al., 2007; Talukder et al., 2008). However, the results of previous research on Bangladesh were not satisfactory. Therefore, it is rationale to improve the outcome of IVF of IVM oocytes derived from indigenous Zebu cows of Bangladesh. Considering the above mentioned facts, the present study was carried out to determine an effective fertilization media, sperm separation method and sperm capacitation agent for optimum fertilization rate of IVM oocytes of indigenous zebu cows in Bangladesh.

\section{MATERIALS AND METHODS}

\section{Study period}

The study was conducted using samples collected from local slaughter houses of Mymensingh City Corporation area and the experiments were carried out in Community-based Dairy Veterinary Foundation (CDVF) laboratory under the Department of Surgery and Obstetrics, Faculty of Veterinary Science, Bangladesh Agricultural University, Mymensingh during the period from January 2015 to December 2016.

\section{Experimental design}

The experimental procedure was approved by the Animal Welfare and Experimentation Ethics Committee of Bangladesh Agricultural University, Mymensingh, Bangladesh (AWEEC/BAU/2020/13).

To determine an effective fertilization medium, the COCs and spermatozoa were co-incubated in BSA supplemented TALP, TCM-199 and BO medium at $38.5^{\circ} \mathrm{C}$ in a humidified atmosphere of $5 \% \mathrm{CO}_{2}$ in air for $18-20$ hours.

To determine an effective sperm separation method, separation of spermatozoa from frozen thawed semen samples was done by either washing, swim up and density gradient methods followed by insemination.

To determination an effective sperm capacitating agent, IVF medium supplemented with the heparin, mixture of penicillamine, hypotaurine and epinephrine (PHE) or the combination of heparin with PHE were used for fertilization. The IVF medium without supplementation of $\mathrm{ca}^{-}$ pacitating agent was used as control. The concentration of heparin was $10 \mu \mathrm{g} / \mathrm{mL}$ and PHE contained $20 \mu \mathrm{M} \mathrm{D}$ penicillamine, $10 \mu \mathrm{M}$ hypotaurine and $1 \mu \mathrm{M}$ epinephrine.

\section{Chemicals and media}

The media constitutes, chemicals and reagents were purchased from Sigma-Aldrich Company (Saint Louis, MO, USA). Media was prepared using standard protocol following aseptic measures. Only cell culture tested 
chemicals were used to formulate the media. All the media were filtered using $0.22 \mu \mathrm{m}$ poor size filter (Durapure ${ }^{\circledR}$ membrane filter, Ireland) and equilibrated at $38.5^{\circ} \mathrm{C}$ with $5 \% \mathrm{CO}_{2}$ in humidified air for at least 2 hours before use.

\section{Collection of oocytes and maturation}

Ovaries of indigenous zebu cows were collected from local slaughterhouses within two hours after slaughtering and kept in thermo-flask containing $37^{\circ} \mathrm{C}$ warmed normal saline followed by transportation to the laboratory within one hour. The ovaries were rinsed three times with warm $\left(37^{\circ} \mathrm{C}\right)$ normal saline. The follicular fluid was aspirated using an 18 gauge needle (TERUMO ${ }^{\circledR}$, Beijing, China) fitted with a $10 \mathrm{~mL}$ disposable plastic syringe (JMI Syringes and Medical Devices Ltd ${ }^{\circledR}$, Chauddagram, Comilla, Bangladesh) and the aspirated follicular fluid was transferred in a $60 \mathrm{~mm}$ petri dish (Greiner bio-one, Frickenhausen, Germany) and kept for 5 minutes for settlement. After settlement, the supernatant follicular fluid was discarded and the sediment was diluted with HEPES-buffered tissue culture medium (TCM) 199 supplemented with bovine serum albumin (BSA). The cumulus oocytes complex (COCs) having more than three compact cumulus cell layers with homogenous cytoplasm were selected under a stereomicroscope (LABOMED, USA) for maturation.

For IVM of oocytes, bicarbonate buffered TCM 199 was used as basic media for oocytes maturation (Bhuiyan et al., 2007). For maturation culture, $50 \mu \mathrm{L}$ droplets of maturation medium were prepared in $35 \mathrm{~mm}$ petri dish (FALCON, Becton Dickinson Labware, USA) and covered with embryo tested mineral oil. Then the petri dish was kept in $\mathrm{CO}_{2}$ incubator until oocyte cultured for maturation. The maturation medium TCM 199 were supplemented with FSH and FBS for oocytes maturation.

\section{Preparation of IVF culture droplets}

The media for fertilization were bicarbonate buffered TCM 199, TALP (Fukui, 1990) and BO (Bracket and Oliphant, 1975) medium supplemented with BSA as per experimental design. For fertilization culture, $43 \mu \mathrm{L}$ droplets of fertilization media were prepared in $35 \mathrm{~mm}$ of petri dish. The culture droplets were covered with mineral oil and kept in $\mathrm{CO}_{2}$ incubator at least two hours before spermoocytes co-incubation.

\section{Sperm preparation}

Frozen semen straws were purchased from Central AI Laboratory, Saver, Dhaka and Research Animal Farm, Department of Surgery and Obstetrics, Bangladesh Agricultural University, Mymensingh. Two $0.25 \mathrm{~mL}$ French straws were thawed at $37^{\circ} \mathrm{C}$ for 15 seconds and motility was evaluated under phase contrast microscope. After evaluation, semen sample was subjected to different sperm separation protocols using capacitation TALP (Cap-TALP) medium. For separation of motile viable sperm from thawed semen, three sperm separation methods were used according to experimental design. After separation of motile sperm, sperm concentration in the pellet was determine by using hemocytometer and adjusted to $1.0 \times$ $10^{6} \mathrm{spz} / \mathrm{mL}$ in Cap-TALP medium.

\section{Addition of sperm capacitation agent in fertilization medium}

Heparin or mixture of penicillamine, hypotaurine and epinephrine (PHE) or the combination of heparin with PHE was used as sperm capacitation agent as per experimental design. The capacitation agents were added in the oocyte containing IVF TALP medium before insemination.

\section{In vitro insemination}

After in vitro maturation, the expanded COCs were removed from the IVM culture drops, washed 3 times in washing TALP and once rinsed in fertilization media. Seven to nine COCs were transferred into each $43 \mu \mathrm{L}$ IVF culture droplets. A $4 \mu \mathrm{L}$ of aliquot of $1.0 \times 10^{6} / \mathrm{mL}$ sperm suspension was added in each droplet. Oocytes and spermatozoa were co-incubated at $38.5^{\circ} \mathrm{C}$ in a humidified atmosphere of $5 \% \mathrm{CO}_{2}$ in air for $18-20$ hours.

\section{Evaluation of oocytes fertilization}

The fertilization of oocytes was evaluated by examination of cleavage rate after 24 hours of IVC of presumptive zygotes. Briefly, after 18-20 hours of sperm oocytes coincubation, the presumptive zygotes were removed from IVF culture droplets followed by denuding by repeated pipetting in IVC washing medium in presence of $0.2 \%$ hyaluronidase. After denuding the presumptive zygotes were three times washed with IVC washing medium and once rinsed culture medium. The IVC medium for development of embryos was mSOF (Choi et al., 2002) supplemented with $0.3 \%(\mathrm{w} / \mathrm{v}) \mathrm{BSA}$ and seven to nine zygotes were cul- 
tured in $25 \mu \mathrm{L}$ droplets of medium covered with embryo tested mineral oil.

\section{Statistical analysis}

The data were entered in Microsoft Excel spreadsheet and descriptive statistics was performed. Analysis of variance followed by least significant difference test was done to find out the significant differences between groups. Z test was done to determine the significant effect on cleavage rates within the groups using SPSS Version 20. The difference between groups was considered significant when $p$ value was $<0.05$.

\section{RESULTS}

\section{Determination of an effective IVF medium for fertilization of mature oocytes}

Effects of fertilization media on cleavage rate of presumptive zygotes are presented in Table 1 . The cleavage rates of presumptive zygotes produced using TCM 199, TALP and BO as fertilization media were 47.5, 63.3 and $59.8 \%$, respectively. The difference in cleavage rate between TALP and TCM-199 fertilization media was statistically significant $(p<0.05)$.

\section{Determination of an effective sperm separation method for IVF of IVM oocytes}

Effects of sperm separation methods on cleavage rate of presumptive zygotes are presented in Table 2 . The cleavage rates of presumptive zygotes produced by insemination of spermatozoa separated by centrifugation, swim up and percoll gradient methods were 51.6, 60.8 and $62.3 \%$, respectively. The difference in cleavage rate between spermatozoa separated by percoll gradient and centrifugation method was statistically significant $(p<0.05)$.

Table 1. Effects of fertilization media on cleavage rate of indigenous zebu cows zygotes

\begin{tabular}{lccc}
\hline $\begin{array}{c}\text { Fertilization } \\
\text { media }\end{array}$ & $\begin{array}{c}\text { No. of presumptive } \\
\text { zygotes cultured }\end{array}$ & $\begin{array}{c}\text { No. of presumptive } \\
\text { zygotes cleaved }\end{array}$ & $\begin{array}{c}\text { Cleavage } \\
\text { rate (\%) }\end{array}$ \\
\hline TCM 199 & 80 & 38 & $47.5^{\mathrm{b}}$ \\
TALP & 90 & 57 & $63.3^{\mathrm{a}}$ \\
BO & 97 & 58 & $59.8^{\mathrm{a}, \mathrm{b}}$ \\
\hline
\end{tabular}

Number of replicates is 5 .

${ }^{a, b}$ Values with superscript letter within same column differ significantly from each other $(p<0.05)$.

\section{Determination of an effective sperm capacitation agent for IVF medium of IVM oocytes}

Effects of sperm capacitation agents on cleavage rate of presumptive zygotes are presented in Table 3. The cleavage rates of presumptive zygotes produced by sperm capacitated by no capacitation agent, heparin, PHE and heparin in combination PHE were 40.9, 56.2, 50.5 and $61.3 \%$, respectively. The difference in cleavage rate between control and heparin or heparin + PHE was statistically significant $(p<0.05)$.

\section{DISCUSSION}

The research work was undertaken to determine an effective fertilization medium, sperm separation method and sperm capacitating agent for optimum IVF rates of indigenous zebu cow oocytes. In this experiment, TCM 199, TALP and BO medium were used for fertilization of oocytes of indigenous Zebu cows and cleavage rate was determined to evaluate the efficacy of fertilization medium. Further development of the embryos to morula and blastocyst stage was evaluated in another study related to IVC media. When compared, higher cleavage rate was

Table 2. Effects of sperm separation methods on cleavage rate of zygotes of indigenous zebu cows

\begin{tabular}{lccc}
\hline $\begin{array}{c}\text { Sperm separa- } \\
\text { tion methods }\end{array}$ & $\begin{array}{c}\text { No. of presumptive } \\
\text { zygotes cultured }\end{array}$ & $\begin{array}{c}\text { No. of presumptive } \\
\text { zygotes cleaved }\end{array}$ & $\begin{array}{c}\text { Cleavage } \\
\text { rate (\%) }\end{array}$ \\
\hline Centrifugation & 161 & 83 & $51.6^{\mathrm{b}}$ \\
Swim up & 237 & 144 & $60.8^{\mathrm{a}, \mathrm{b}}$ \\
Percoll gradient & 239 & 149 & $62.3^{\mathrm{a}}$ \\
\hline
\end{tabular}

Number of replicates is 10 .

a,b Values with superscript letter within same column differ significantly from each other $(p<0.05)$.

Table 3. Effects of sperm capacitation agents in IVF medium on cleavage rate of zygotes indigenous zebu cows

\begin{tabular}{lccc}
\hline $\begin{array}{c}\text { Capacitation } \\
\text { agent }\end{array}$ & $\begin{array}{c}\text { No. of presumptive } \\
\text { zygotes cultured }\end{array}$ & $\begin{array}{c}\text { No. of presumptive } \\
\text { zygotes cleaved }\end{array}$ & $\begin{array}{c}\text { Cleavage } \\
\text { rate (\%) }\end{array}$ \\
\hline Control (no agent) & 110 & 45 & $40.9^{\mathrm{b}}$ \\
Heparin & 105 & 59 & $56.2^{\mathrm{b}}$ \\
PHE & 101 & 51 & $50.5^{\mathrm{a}, \mathrm{b}}$ \\
Heparin + PHE & 106 & 65 & $61.3^{\mathrm{a}}$ \\
\hline
\end{tabular}

Number of replicates is 8.

PHE: Penicillamine, hypotaurine and epinephrine.

${ }^{a, b}$ Values with superscript letter within same column differed significantly from each other $(p<0.05)$. 
observed in oocytes fertilized in TALP media than that of TCM-199. The media used for IVF of oocytes must be capable of providing conditions to the secondary oocytes and capacitated spermatozoa which will permit sperm penetration easily followed by development of zygotes. The commonly used media for IVF are TALP medium (Parrish et al., 1986), BO medium (Brackett and Oliphant, 1975), TCM-199 (Al-Hafedh et al., 2018) and synthetic oviduct fluid (SOF) medium (Iwata et al., 2004). Deb et al. (2016) also used TALP medium for IVF of Zebu cows oocytes and obtained similar fertilization rate as present study. Additionally, higher cleavage rate after fertilization in TALP medium than that of TCM 199 was reported elsewhere (Ferre et al., 2015).

The fertilization rate of oocytes of indigenous Zebu cows was influenced by the sperm separation methods in the present investigation as indicated by higher cleavage rate in oocytes fertilized by spermatozoa separated by percoll gradient method than that of centrifugation method. In this experiment, three sperm separation methods namely centrifugation, swim up and percoll gradient methods were used for separation of motile and viable spermatozoa for IVF. In agreement with the present study, Mendes et al. (2003) obtained higher cleavage rates and embryo production when spermatozoa were prepared by percoll compared to washing (centrifugation) method. Similarly, the percoll gradient method resulted in higher cleavage and blastocyst formation rates than that did the swim-up procedure in goats (Rho et al., 2001). In contrast, Parrish et al. (1995) reported higher cleavage rates of bovine oocytes when spermatozoa were separated by swim-up compared to percoll treatment although higher recovery of motile spermatozoa in Percoll gradient technique was obtained compared to the swim-up method. Jamil et al. (2007) also found higher cleavage when the spermatozoa were prepared by swim-up method in Buffalo compared to other methods. Some study also indicated that the percoll (Correa and Zavos, 1996; Prakash et al., 1998) and swim-up (Palomo et al., 1999) method yielded a qualitative superior sperm sample with significantly more motile, viable and morphologically normal spermatozoa than the washing (centrifugation) procedure. The lower fertilization rate in oocytes inseminated by spermatozoa separated by washing method may be due to oxidative cell damage caused by ROS generated in packaged cells after centrifugation. However, Avery and Greve
(1995) reported that the washing method can be used for sperm preparation to fertilize bovine oocytes in vitro with no detrimental effect on cleavage rate.

The IVF rate of indigenous Zebu cows oocytes were influenced by the sperm capacitating agent in the present study as indicated by obtaining higher cleavage rate of oocytes inseminated by spermatozoa capacitated by combination of heparin and PHE compared to control (no capacitating agent). In agreement with this study, cleavage rate was higher when IVF media was supplemented with combination of heparin and PHE than that of other agents (Hasler and Stokes, 2012; Goncalves et al., 2014). Sperm capacitation and the acrosome reaction are necessary physiological events that enable the sperm cell to penetrate the zona pellucida of the ovum to initiate the fertilization process (Chang, 1984). Capacitation involves biochemical changes in the outer sperm membranes that allow the acrosome reaction to occur. The IVF media when supplemented with heparin and mixture of PHE shortened the time required for oocyte penetration and increased the cleavage rate compared to the results without PHE (Miller et al., 1994). Jaakma et al. (1997) also observed that a significantly higher proportion of bovine oocytes developed to blastocyst stage after insemination with spermatozoa prepared by swim-up in TALP supplemented with heparin than by centrifugation in BO supplemented with caffeine.

Sperm capacitation and the acrosome reaction are dependent on the increase of intracellular calcium in sperm (Monaco et al., 2009). Heparin binds to sperm and induces changes in its intracellular environment (Lane et al., 1999) which results in Ca2+ uptake and increase in intracellular free calcium and intracellular $\mathrm{pH}$ followed by initiation of acrosome reaction (Handrow et al., 1989). Moreover, some studies have shown that the individual components of PHE solution increase sperm motility (Leibfried and Bavister, 1982) and the percentage that undergo acrosome reaction (Meizel, 1985). Penicillamine has also been shown to increase the percentage of spermatozoa that undergo acrosome reaction when used in the presence of epinephrine (Meizel, 1985). Hypotaurine increases sperm motility and oocyte penetration (Leibfried and Bavister, 1982), while the combination of epinephrine and hypotaurine increases the oocyte penetration rate by bovine spermatozoa and subsequent pronuclei formation (Ball et al., 1983). Epinephrine has been shown 
to stimulate sperm motility, to induce acrosome reaction, and to enhance oocyte penetration during IVF (Leibfried and Bavister, 1982; Meizel, 1985).

\section{CONCLUSIONS}

TALP based medium and separation of spermatozoa by percoll gradient method followed by capacitation with combination of heparin and PHE are preferable to produce IVF embryos of indigenous Zebu cows in Bangladesh.

\section{CONFLICTS OF INTEREST}

No potential conflict of interest relevant to this article was reported.

\section{ACKNOWLEDGEMENTS}

The research project was funded by the Ministry of Education, People's Republic of Bangladesh (FY 2012-13 to 2014-15)

\section{AUTHOR CONTRIBUTIONS}

Mohammad Moshiur Rahman conducted the research and wrote the manuscript. Md. Masudur Rahman assisted the first author to conduct the research. Nasrin Sultana Juyena acted as the Co-supervisor of the research. Mohammad Musharraf Uddin Bhuiyan supervised the research and prepared the manuscript.

\section{AUTHOR'S POSITION AND ORCID NO.}

\author{
MM Rahman, Ph.D. Student, \\ https://orcid.org/0000-0002-0406-7654 \\ MM Rahman, Ph.D. Student, \\ https://orcid.org/0000-0002-5769-7510 \\ NS Juyena, Professor, \\ https://orcid.org/0000-0003-0331-0998 \\ MMU Bhuiyan, Professor, \\ https://orcid.org/0000-0002-0870-186X
}

\section{REFERENCES}

Adeoya-Osiguwa SA and Fraser LR. 2002. Capacitation statedependent changes in adenosine receptors and their regu- lation of adenylyl cyclase/cAMP. Mol. Reprod. Dev. 63:245255.

Al-Hafedh S, Mohammed T, Al-Tami I. 2018. Maturation, fertilization and implantation of cattle ova cultured in different media. Eurasia Proc. Sci. Technol. Eng. Math. 3:181-188.

Avery B and Greve T. 1995. Impact of Percoll on bovine spermatozoa used for in vitro insemination. Theriogenology 44:871878.

Ball GD, Leibfried ML, Lenz RW, Ax RL, Bavister BD, First NL. 1983. Factors affecting successful in vitro fertilization of bovine follicular oocytes. Biol. Reprod. 28:717-725.

Bavister BD. 2002. Early history of in vitro fertilization. Reproduction 124:181-196.

Bhuiyan MM, Kang SK, Lee BC. 2007. Effects of fructose supplementation in chemically defined protein-free medium on development of bovine in vitro fertilized embryos. Anim. Reprod. Sci. 102:137-144.

Brackett BG and Oliphant G. 1975. Capacitation of rabbit spermatozoa in vitro. Biol. Reprod. 12:260-274.

Centola GM, Herko R, Andolina E, Weisensel S. 1998. Comparison of sperm separation methods: effect on recovery, motility, motion parameters, and hyperactivation. Fertil. Steril. 70:1173-1175.

Chang MC. 1984. The meaning of sperm capacitation. A historical perspective. J. Androl. 5:45-50.

Choi YH, Lee BC, Lim JM, Kang SK, Hwang WS. 2002. Optimization of culture medium for cloned bovine embryos and its influence on pregnancy and delivery outcome. Theriogenology 58:1187-1197.

Correa JR and Zavos PM. 1996. Preparation and recovery of frozen-thawed bovine spermatozoa via various sperm selection techniques employed in assisted reproductive technologies. Theriogenology 46:1225-1232.

Deb GK, Dey SR, Nahar TN, Khan MYA, Rahman MM. 2016. In vitro production of bovine blastocyst with oocyte collected from abattoir ovary. Bangladesh J. Anim. Sci. 45:31-35.

Ferré LB, Bogliotti Y, Chitwood JL, Fresno C, Ortega HH, Kjelland ME, Ross PJ. 2015. Comparison of different fertilisation media for an in vitro maturation-fertilisation-culture system using flow-cytometrically sorted $\mathrm{X}$ chromosome-bearing spermatozoa for bovine embryo production. Reprod. Fertil. Dev. 28:1695-1703.

Fukui Y. 1990. Effect of follicle cells on the acrosome reaction, fertilization, and developmental competence of bovine oocytes matured in vitro. Mol. Reprod. Dev. 26:40-46.

Gonçalves FS, Barretto LS, Arruda RP, Perri SH, Mingoti GZ. 2014. Heparin and penicillamine-hypotaurine-epinephrine (PHE) solution during bovine in vitro fertilization procedures impair the quality of spermatozoa but improve normal oocyte fecundation and early embryonic development. In Vitro Cell. Dev. Biol. Anim. 50:39-47.

Handrow RR, First NL, Parrish JJ. 1989. Calcium requirement and increased association with bovine sperm during capacitation by heparin. J. Exp. Zool. 252:174-182.

Hasler JF and Stokes JE. 2012. Effect of the presence or absence 
of percoll centrifugation; penicillamine, hypotaurine, and epinephrine; and heparin on in vitro production of bovine embryos. Reprod. Fertil. Dev. 25:259.

Islam MF, Bhuiyan MMU, Banu TA, Bhattacharjee J, Shamsuddin M. 2007. In vitro maturation and fertilization of oocytes in zebu cattle. Bangladesh J. Vet. Med. 41:58-76.

Iwata H, Hashimoto S, Ohota M, Kimura K, Shibano K, Miyake M. 2004. Effects of follicle size and electrolytes and glucose in maturation medium on nuclear maturation and developmental competence of bovine oocytes. Reproduction 127:159-164.

Jaakma U, Zhang BR, Larsson B, Niwa K, Rodriguez-Martinez H. 1997. Effects of sperm treatments on the in vitro development of bovine oocytes in semidefined and defined media. Theriogenology 48:711-720.

Jamil H, Samad HA, Qureshi ZI, Rehman N, Lodhi LA. 2007. Effect of bull and sperm preparation method on in vitro fertilization of buffalo oocytes. Pak. Vet. J. 27:29-34.

Karadjole M, Getz I, Samardžija M, Maćešić N, Matković M, Makek Z, Karadjole T, Baćić G, Dobranić T, Poletto M. 2010. The developmental competence of bovine immature oocytes and quality of embryos derived from slaughterhouse ovaries or live donors by ovum pick up. Vet. Arch. 80:445454.

Lane M, Thérien I, Moreau R, Manjunath P. 1999. Heparin and high-density lipoprotein mediate bovine sperm capacitation by different mechanisms. Biol. Reprod. 60:169-175.

Leibfried ML and Bavister BD. 1982. Effects of epinephrine and hypotaurine on in vitro fertilization in the golden hamster. J. Reprod. Fertil. 66:87-93.

Leibfried-Rutledge ML, Critser ES, Parrish JJ, First NL. 1989. In vitro maturation and fertilization of bovine oocytes. Theriogenology 31:61-74.

Meizel S. 1985. Molecules that initiate or help stimulate the acrosome reaction by their interaction with the mammalian sperm surface. Am. J. Anat. 174:285-302.

Mendes JO Jr, Burns PD, De La Torre-Sanchez JF, Seidel GE Jr. 2003. Effect of heparin on cleavage rates and embryo production with four bovine sperm preparation protocols. Theriogenology 60:331-340.

Miller GF, Gliedt DW, Rakes JM, Rorie RW. 1994. Addition of penicillamine, hypotaurine and epinephrine (PHE) or bovine oviductal epithelial cells (BOEC) alone or in combination to bovine in vitro fertilization medium increases the subsequent embryo cleavage rate. Theriogenology 41:689696.

Monaco E, Gasparrini B, Boccia L, De Rosa A, Attanasio L, Zicarelli L, Killian G. 2009. Effect of osteopontin (OPN) on in vitro embryo development in cattle. Theriogenology 71:450457.

Morrell JM and Rodriguez-Martinez H. 2010. Practical applications of sperm selection techniques as a tool for improving reproductive efficiency. Vet. Med. Int. 2011:894767.

Palomo MJ, Izquierdo D, Mogas T, Paramio MT. 1999. Effect of semen preparation on IVF of prepubertal goat oocytes. Theriogenology 51:927-940.

Parrish JJ, Susko-Parrish JL, Leibfried-Rutledge ML, Critser ES, Eyestone WH, First NL. 1986. Bovine in vitro fertilization with frozen-thawed semen. Theriogenology 25:591-600.

Prakash P, Leykin L, Chen Z, Toth T, Sayegh R, Schiff I, Isaacson K. 1998. Preparation by differential gradient centrifugation is better than swim-up in selecting sperm with normal morphology (strict criteria). Fertil. Steril. 69:722-726.

Rho GJ, Hahnel AC, Betteridge KJ. 2001. Comparisons of oocyte maturation times and of three methods of sperm preparation for their effects on the production of goat embryos in vitro. Theriogenology 56:503-516.

Rodriguez-Martinez H, Larsson B, Pertoft H. 1997. Evaluation of sperm damage and techniques for sperm clean-up. Reprod. Fertil. Dev. 9:297-308.

Sakkas D. 2001. Evaluation of embryo quality: a strategy for sequential analysis of embryo development with the aim of single embryo transfer. In: Gardner DK, Weissman A, Howles CM, Shoham Z (Eds.), Textbook of Assisted Reproductive Techniques. Martin Dunitz, London, pp. 228-229.

Samardžija M, Dobranić T, Karadjole M, Getz I, Vince S, Graćner D, Maćešić N, Filaković I. 2006. The efficacy of gradient Percoll ${ }^{\circledR}$ on bull sperm separation for in vitro fertilization. Vet. Arch. 76:37-44.

Talukder AK, Shamsuddin M, Rahman MB, Bari FY, Parish JJ. 2008. Normal and abnormal fertilisation of zebu cattle oocytes in vitro. J. Emb. Trans. 24:89-95. 